\title{
Ti-Ni Rods with Variable Stiffness for Spine Stabilization: Manufacture and Biomechanical Evaluation
}

\author{
Vladimir Brailovski $^{2,1} \cdot$ Yann Facchinello ${ }^{1,2} \cdot$ Martin Brummund $^{1,2} \cdot$ \\ Yvan Petit $^{1,2} \cdot$ Jean-Marc Mac-Thiong ${ }^{2,3}$
}

Published online: 24 February 2016

(c) ASM International 2016

\begin{abstract}
A new concept of monolithic spinal rods with variable flexural stiffness is proposed to reduce the risk of adjacent segment degeneration and vertebral fracture, while providing adequate stability to the spine. The variability of mechanical properties is generated by locally annealing $\mathrm{Ti}-\mathrm{Ni}$ shape memory alloy rods. Ten-minute Joule effect annealing allows the restoration of the superelasticity in the heated portion of the rod. Such processing also generates a mechanical property gradient between the heated and the unheated zones. A numerical model simulating the annealing temperature and the distributions of the mechanical properties was developed to optimize the Joule-heating strategy and to modulate the rod's overall flexural stiffness. Subsequently, the rod model was included in a finite element model of a porcine lumbar
\end{abstract}

Vladimir Brailovski

vladimir.brailovski@etsmtl.ca

Yann Facchinello

yann.facchinello.1@ens.etsmtl.ca

Martin Brummund

martin.brummund.1@ens.etsmtl.ca

Yvan Petit

yvan.petit@etsmtl.ca

Jean-Marc Mac-Thiong

macthiong@gmail.com

1 École de Technologie Supérieure, 1100 Notre-Dame Street West, Montreal, QC H3C 1K3, Canada

2 Research Center, Hôpital du Sacré-Cœur de Montréal, 5400 Gouin Boul. West, Montreal, QC H4J 1C5, Canada

3 Department of Surgery, Faculty of Medicine, University of Montreal, Pavillon Roger-Gaudry, S-749, Succ. Centre-ville, C.P. 6128, Montreal, QC H3C 3J7, Canada spine to study the effect of the rod's stiffness profiles on the spinal biomechanics.

Keywords NiTi - Materials - Mechanical behaviour . SMA $\cdot$ Superelasticity

\section{Introduction}

Spinal disorders can be treated by several methods, including fusion surgery. Rigid posterior instrumentations are commonly used to relieve chronic back pain, fractures, instability, and neurological injury. These strong instrumentations are used to prevent motion in the instrumented segment and to avoid implant failure [1, 2]. However, this type of implant creates a significant stress concentration between the instrumented and the intact segments, which results from a difference in their mobility. Such a stress concentration leads to adjacent segment degeneration, proximal junctional kyphosis or even fractures [3, 4].

In order to relieve the stress observed on the adjacent segments, the so-called dynamic stabilization systems have been proposed. Such systems are designed to provide more motion at the instrumented level and to reduce the mobility at the adjacent level. However, these implants have yet to prove their efficiency as they are frequently associated with implant failure, inadequate stability or persistent adjacent segment degeneration [4-6].

An ideal configuration would combine strong stabilization in the fusion zone with a gradual mobility transition between the instrumented and intact segments. Such a transition could potentially be obtained by varying the stiffness along the rod. In this study, the use of Ti-Ni shape memory alloy (SMA) is proposed to manufacture monolithic rods with variable flexural stiffness. 
Nearly equiatomic Ti-Ni alloys can exhibit drastically different mechanical behaviours at a given temperature, depending on their thermomechanical processing. $\mathrm{Ti}-\mathrm{Ni}$ parts are commonly produced using a specific sequence of plastic deformation and thermal treatments [7]. It has been shown that when the plastic deformation is performed at room temperature, a large number of defects induced in the material suppress the superelasticity, and a conventional elastoplastic mechanical behaviour is observed. Post-deformation annealing (PDA) is therefore needed to restore the superelasticity [8].

PDAs are usually applied on complete parts, but can also be used to reduce the defect density in a confined zone of a monolithic SMA product. Local annealing can be carried out using several techniques, including Joule, laser or induction heating [9-11]. In particular, it has been shown that both elastoplastic and superelastic behaviours could be observed in a monolithic Ti-Ni Ø2-mm wire subjected to local Joule effect post-deformation annealing (J-PDA). A gradual transition between these mechanical behaviours is obtained due to a thermal gradient created by local annealing [12].

In this work, local Joule effect annealing is proposed to produce monolithic rods with variable flexural stiffness. Such rods could combine a strong stabilization capacity in the instrumented segment, while reducing the stress on the adjacent segment thanks to their softer superelastic extremities.

First, this paper describes the manufacture of the rod. Then, finite element models simulating the biomechanics of a porcine spine segment stabilized with variable-stiffness $\mathrm{Ti}-\mathrm{Ni}$ rods are described and validated.

\section{Methodology}

\section{Materials and Processing}

Ti-55.94Ni (wt\%) 5.5-mm diameter wire was supplied by Johnson Matthey Medical (San Jose, PA, USA) in two metallurgical conditions: as-drawn (hardened material, cold worked strain of about $30 \%$ ) and annealed (superelastic material).

\section{Assessment of the Properties-Modification Capacity of J-PDA}

Joule effect annealing was performed on a custom-made bench using an RE30-170 power supply capable of delivering $170 \mathrm{~A}$ at $30 \mathrm{~V}$ (Matsusada Precision, Japan). Temperature was measured using a type $\mathrm{K}$ thermocouple (TTK-36-SLE, Omega Eng. Inc, USA.) and an E60 thermal imager (FLIR Systems, USA). A photograph of the bench is presented in Fig. 1.

Hardened Ti-Ni rods subjected to Joule effect annealing at $260,345,430,500$ and $585{ }^{\circ} \mathrm{C}$ for 10 min were used to assess the property-modification capacity of J-PDA. Tensile testing was performed on $25 \mathrm{~cm}$ long rods using an MTS Alliance testing apparatus (MTS, MN, USA), with a crosshead speed of $0.1 \mathrm{~mm} / \mathrm{s}$. The rods were strained twice up to $6 \%$, and released before loading to failure. Such a sequence was used to characterize both the superelastic and the conventional elastoplastic behaviour.

Figure $2 \mathrm{a}$ shows the tensile stress-strain diagrams of specimens subjected to 10 -min Joule-effect PDA at various temperatures. The stress-strain diagrams corresponding to annealing at $430{ }^{\circ} \mathrm{C}$ are used to explain how parameters of the finite element analysis superelastic material law were obtained (see "Numerical Modelling" section for details). Figure 2b, c illustrate evolution of the Young's modulus under loading $\left(\mathrm{E}_{\mathrm{Aus}}\right)$ and of the onset transformation stress $\left(\sigma_{\mathrm{s}, \mathrm{t}}^{\mathrm{AS}}\right)$ measured for the 2 nd loading cycle as functions of the annealing temperature. It can be seen that starting from the 2nd loading cycle, the hardened material exhibits behaviour which can be called linear superelasticity. Tenminute J-PDA at $430{ }^{\circ} \mathrm{C}$ restores plateau-like superelastic behaviour of the material with a Young's modulus of $36 \mathrm{GPa}$ and a critical stress of $350 \mathrm{MPa}$. On the contrary, 10 -min $\mathrm{J}$-PDA at $585^{\circ} \mathrm{C}$ results in a stiff elastoplastic material with a Young's modulus of $85 \mathrm{GPa}$.

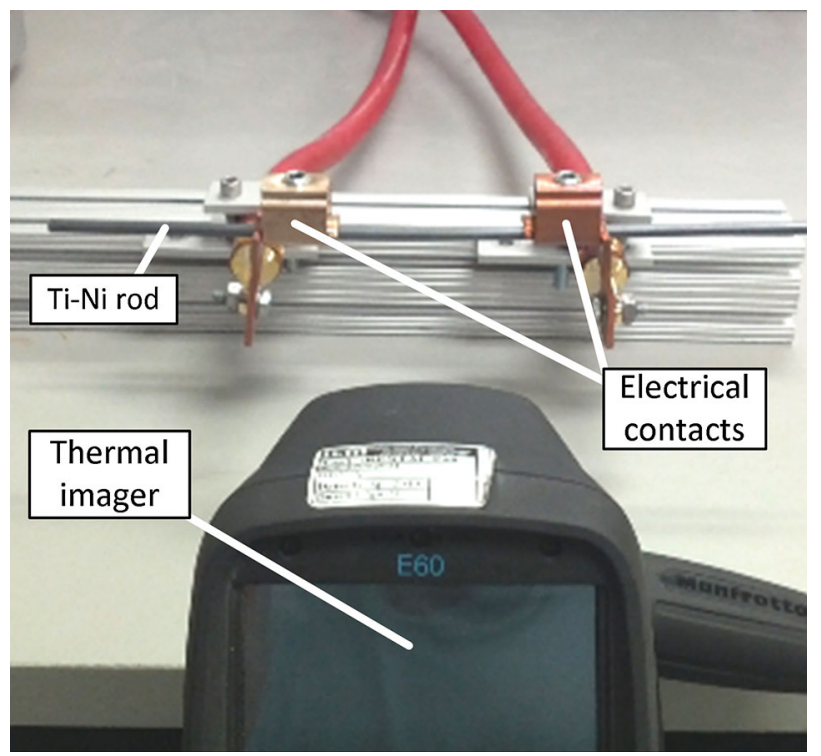

Fig. 1 Photograph of the Joule-heating annealing setup 


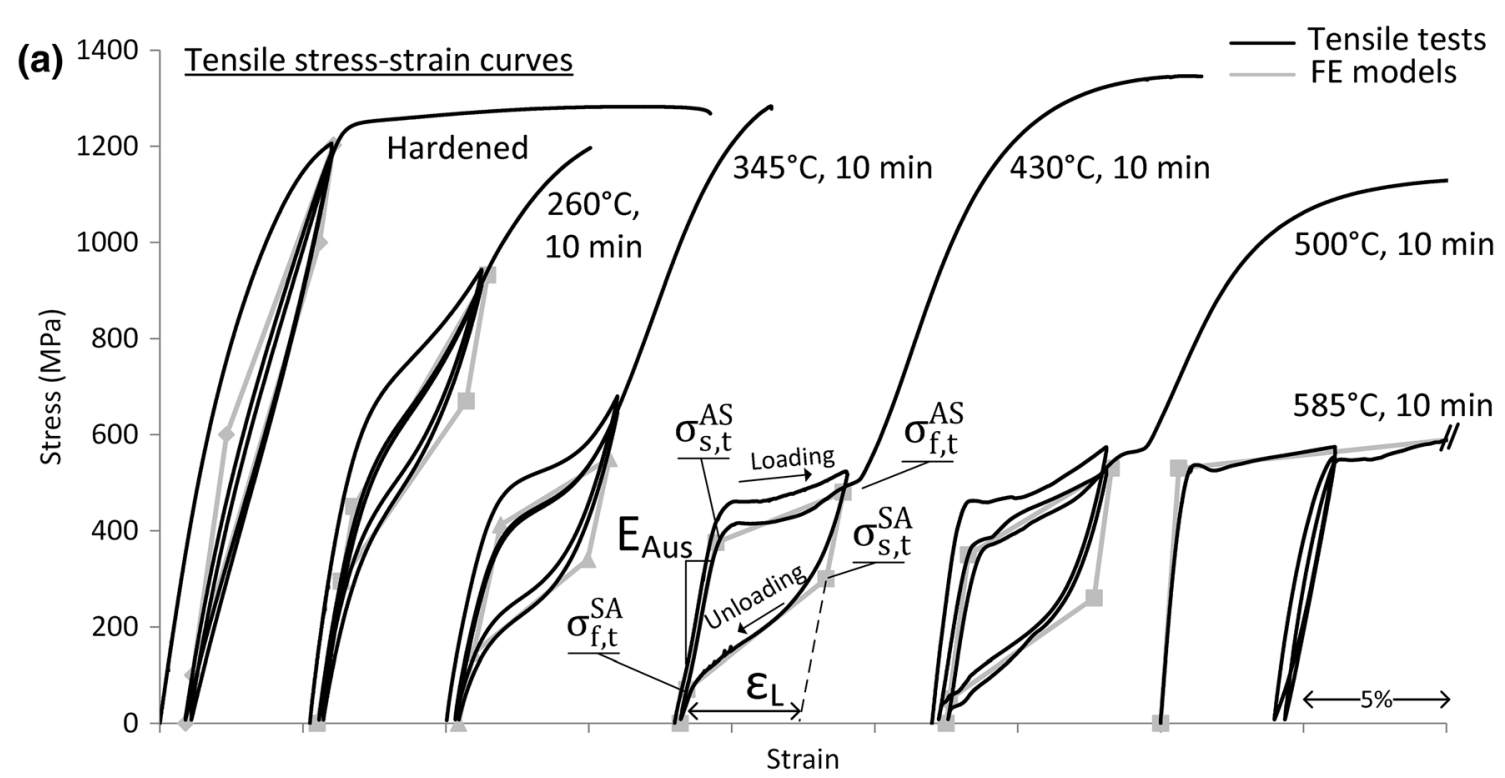

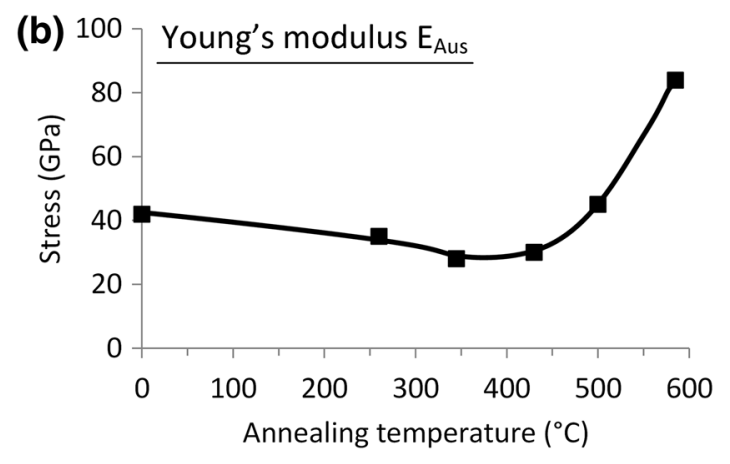

Fig. 2 a Stress-strain diagram of Ti-55.94 wt\% Ni annealed at different temperatures and the corresponding idealized curves for FE analysis. Characteristic constants are illustrated on the $430{ }^{\circ} \mathrm{C}$,

\section{Numerical Modelling}

\section{Modelling of a Variable-Stiffness Rod}

The numerical simulation of the variable properties was carried out in two steps: i) simulation of the temperature distribution during localized J-PDA, and ii) definition of the mechanical properties gradient using the calculated temperature distribution.

ANSYS 14 finite element analysis software (Ansys Inc., PA, USA) was used to predict the temperature distribution on the rod during J-PDA. The "Thermal-electric" and "Transient Thermal" ANSYS modules were used to simulate the temperature gradient during steady and transient states, respectively. Both models were validated using experimental data.

An ANSYS 14 "Static Structural" module was used to implement the mechanical model of the variable rod. The mechanical behaviour of the SMA was simulated using the

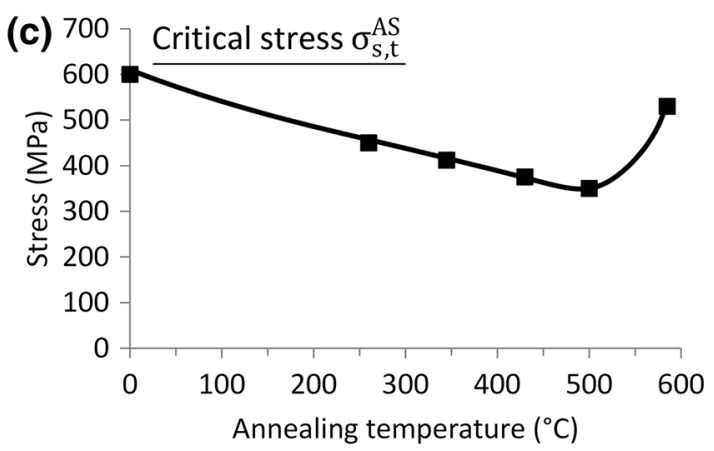

10-min diagram, b Young's modulus, and c critical transformation stress, as functions of the annealing temperature

ANSYS SMA superelastic material law with the following input data: $\sigma_{\mathrm{s}, \mathrm{t}}^{\mathrm{AS}}, \sigma_{\mathrm{f}, \mathrm{t}}^{\mathrm{AS}}, \sigma_{\mathrm{s}, \mathrm{t}}^{\mathrm{SA}}, \sigma_{\mathrm{f}, \mathrm{t}}^{\mathrm{SA}}, \varepsilon_{\mathrm{L}}, \mathrm{E}_{\mathrm{Aus}}$, and $\alpha$. The constants stand for the starting and final stresses of the forward-phase transformation, the starting and final stresses of the reverse-phase transformation, the maximum superelastic plateau strain, and the Young's modulus of austenite, respectively, in tension (see Fig. 2 a for illustration). The last parameter, $\alpha$, models the difference between the material responses in tension and compression; it is related to the values of the corresponding onset stresses for the forward-phase transformation $\left(\sigma_{\mathrm{t}}^{\mathrm{AS}}\right.$ for tension and $\sigma_{\mathrm{c}}^{\mathrm{AS}}$ for compression) by the following expression:

$\alpha=\frac{\sigma_{\mathrm{c}}^{\mathrm{AS}}-\sigma_{\mathrm{t}}^{\mathrm{AS}}}{\sigma_{\mathrm{c}}^{\mathrm{AS}}+\sigma_{\mathrm{t}}^{\mathrm{AS}}}$

A value of $\alpha=0.2$ [13] was considered in this work, which indicates that onset stresses of the forward-phase transformation are $50 \%$ higher in compression than in 
Fig. 3 ANSYS superelastic material law and the corresponding characteristic parameters [14]

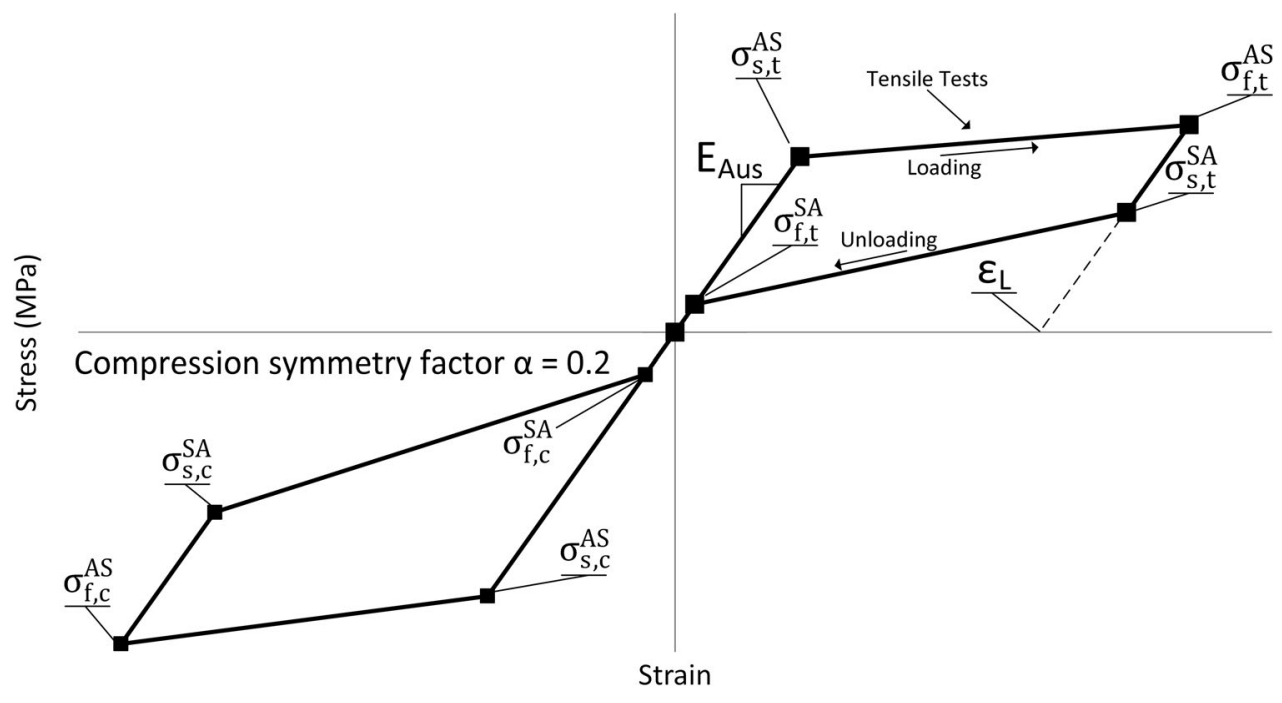

tension (see Fig. 3 where all the parameters used by the ANSYS superelastic material law are illustrated).

Note that the ANSYS superelastic material law was used for the hardened and annealed alloy regardless of whether the material behaves superelastically or not (as it was the case of the alloy annealed at $585{ }^{\circ} \mathrm{C}$ ). In the latter case, the superelastic material law was transformed to the elastoplastic bilinear material law by setting $\sigma_{\mathrm{s}, \mathrm{t}}^{\mathrm{SA}}$ and $\sigma_{\mathrm{f}, \mathrm{t}}^{\mathrm{SA}}$ equal to 0 . Moreover, a maximum plateau strain $\varepsilon_{\mathrm{L}}$ was set to 0.24 , which corresponds to the experimentally measured elongation to failure. Details on the thermal and mechanical models can be found in [14].

A parallel between the annealing temperature profile and the corresponding mechanical behaviour was established using the experimentally obtained stress-strain diagrams for various annealing temperatures presented in Fig. 2. The mechanical model attributes a specific superelastic material law to each element, depending on its temperature, considering the result of the thermal simulation. The software creates a new set of constants using a linear interpolation procedure if the temperature of a given element is between two experimentally obtained sets of data. In this study, 6 sets of constants and five annealing temperatures were defined for the hardened material (see Table 1 in Appendix).

The mechanical model of the heterogeneous rods was validated by comparing the bending profiles of cantilevered rods obtained from calculation and experiment.

\section{Porcine Spine Model}

Seven hundred and sixty computer tomography scan images $(512 \times 512$ pixels, 0.312 -mm spacing in transverse plane) of a cadaveric porcine lumbar spine segment (L1L6) were used for three-dimensional reconstruction. Image
Table 1 Parameters of the ANSYS TB, and SMA material law

\begin{tabular}{lllllll}
\hline Model's & \multicolumn{7}{l}{ Annealing temperature $\left({ }^{\circ} \mathrm{C}\right)$} \\
\cline { 2 - 7 } parameters & Hardened & 260 & 345 & 430 & 500 & 585 \\
\hline$\sigma_{\mathrm{s}, \mathrm{t}}^{\mathrm{AS}}(\mathrm{MPa})$ & 600 & 450 & 412 & 375 & 350 & 530 \\
$\sigma_{\mathrm{f}, \mathrm{t}}^{\mathrm{AS}}(\mathrm{MPa})$ & 1203 & 932 & 550 & 480 & 530 & 683 \\
$\sigma_{\mathrm{s}, \mathrm{t}}^{\mathrm{SA}}(\mathrm{MPa})$ & 1000 & 6670 & 340 & 300 & 260 & 0 \\
$\sigma_{\mathrm{f}, \mathrm{t}}^{\mathrm{SA}}(\mathrm{MPa})$ & 100 & 295 & 145 & 70 & 50 & 0 \\
$\varepsilon_{\mathrm{L}}$ & 0.023 & 0.033 & 0.035 & 0.044 & 0.04 & 0.24 \\
$\mathrm{E}_{\mathrm{Aus}}(\mathrm{GPa})$ & 42 & 40 & 28 & 35 & 35 & 84 \\
$\alpha$ & 0.02 & 0.2 & 0.2 & 0.2 & 0.2 & 0.2 \\
\hline
\end{tabular}

segmentation was carried out using a contour detection tool (Slic-O-matic, Tomovision, Canada). Surface tessellations of L1-L6 were smoothed and filled in CATIA v5 (Dassault Systems, France) to create solid bodies. Intervertebral discs were created using multi-section extrusions between adjacent vertebrae. The nucleus pulposus covers $40 \%$ of the annulus fibrosus ground substance volume in each disc [15]. Annular collagen fibres were accounted for using eight-layered (radial direction) criss-cross-oriented nonlinear tension-only springs. The spinal instrumentation was modelled with $\mathrm{Ti}$ pedicle screws $(6.5 * 45 \mathrm{~mm})$ that were fastened bilaterally in L3-L5. Guided extrusions through the pedicle screw heads were used to model the spinal rods $(5.5 \times 165 \mathrm{~mm})$. Figure 4 illustrates the geometrical model of the non-instrumented and instrumented spine segments.

The geometrical model was imported in ANSYS 15 (Ansys Inc., PA, USA). For the vertebrae and screws, homogenous, isotropic, linear elastic material behaviour was assumed. For the annulus ground substance and 
Fig. 4 Illustration of porcine lumbar model: a posterior view without instrumentation. b posterior view with pedicle screws and spinal rods

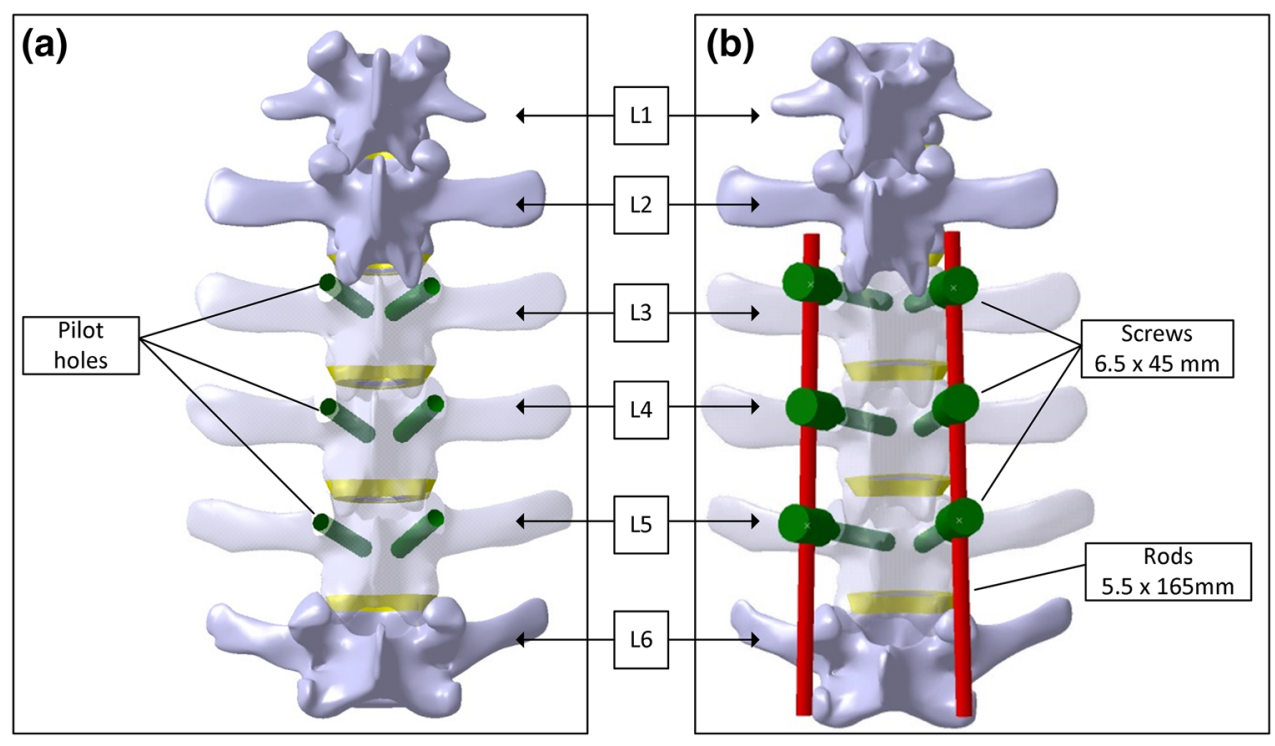

nucleus pulposus, a hyperelastic Mooney-Rivlin model was used. Nonlinear tension-only springs were employed to model the spinal ligaments. All material properties were drawn from the literature. Except for the anterior and posterior longitudinal ligaments and the intervertebral discs, porcine material property data were used for all tissues. Frictionless surface-to-surface contact elements were used to model the facet joints. Additionally, frictionless contacts were assumed between the screw circumference and the pilot holes in the vertebrae. Between the pedicle screw tip and the pilot hole bottom, fixed contacts were assumed. Bonded contacts were also employed to model the contact between the pedicle screw heads and the spinal rods during flexion. During the application of the compressive follower load, these contacts were replaced by frictionless contacts.

Brick and tetrahedral elements were used to mesh the lumbar spine and instrumentation components (see Table 2 in Appendix). A convergence study was carried out to balance between model accuracy and computation time. The meshed geometry was composed of 104,000 nodes and 129,500 elements. The meshed model is illustrated in Fig. 5c.

The caudal half of the L6 vertebra and the spinal rod extremity were rigidly fixed. Loading of the spine segment was done in two steps: a compressive follower load $(400 \mathrm{~N})$ was first applied between the centres of adjacent vertebral bodies (L1-L6). After applying the follower load, $18^{\circ}$ forward flexion (pure moment) was applied on the cephalad endplate of L1 as shown in Fig. 5b, c. Rotation of $18^{\circ}$ is slightly inferior to the range of motion measured by [16] under pure moment loading (7.5 Nm). This precaution was taken to decrease the risk of specimen damage during testing. The softer end of the variable-stiffness rod was always positioned proximally on the spine segments according to our preliminary calculations [17].

The numerical model of the spine segment was validated by comparing its results with the experimentally obtained ranges of motion to establish its adequacy.

In vitro testing was performed on six porcine spine segments in uninstrumented and instrumented conditions. The specimens were loaded in forward flexion motion up to $18^{\circ}$ rotation with a follower load of $400 \mathrm{~N}$.

In the instrumented condition, the spine segments were stabilized using rods with variable properties (VAR) attached to the spine using pedicle screws (PS) $(6.5 \times 45 \mathrm{~mm}, \mathrm{Ti}$, Medtronic, MN, USA) at L5, L4 and L3. Both ends of the specimen were fixed in polyester resin (Bondo, MN, USA), while an aluminium block was used to solidly clamp the caudal ends of both rods (Fig. 5a).

VAR rods were manufactured by applying Joule effect annealing $\left(585^{\circ} \mathrm{C}, 10 \mathrm{~min}\right)$ to the annealed (SE) rods on half of their length. Such processing creates variablestiffness rods with a Young's modulus of $86 \mathrm{GPa}$ in the heated zone and a gradual transition towards the nonheated, compliant $36 \mathrm{GPa}$ superelastic portion of the rod. During in vitro testing, the superelastic portion of the VAR rods was always placed proximally (Fig. 5b). Details and validation of the in vitro testing methodology can be found in $[18,19]$.

\section{Results}

\section{Various Stiffness Rod Model Validation}

Figure 6 shows results of cantilevered bending profiles for a hardened $\mathrm{Ti}-\mathrm{Ni}$ rod subjected, on half of its length, to 
Table 2 Material properties of spine tissues and posterior instrumentation

\begin{tabular}{|c|c|c|c|c|}
\hline & Element type & $\begin{array}{l}\text { Moduli: E (MPa) } \\
\text { Stiffness: K (N/mm) }\end{array}$ & $v$ & Source \\
\hline Vertebrae* & Solid185 & $\mathrm{E}=520,6 \mathrm{MPa}$ & 0.3 & {$[22]$} \\
\hline Annulus & Solid185 & $\begin{array}{l}\mathrm{c} 10=0.18 \\
\mathrm{c} 01=0.045\end{array}$ & 0.45 & {$[23]$} \\
\hline Nucleus & Soild186 & $\begin{array}{l}\mathrm{c} 10=0.12 \\
\mathrm{c} 01=0.03\end{array}$ & 0.49 & \\
\hline $\begin{array}{l}\text { ALL } \\
\text { PLL }\end{array}$ & Combin39 & $\mathrm{K}$ : Nonlinear force-deflection curves & & [24] \\
\hline $\begin{array}{l}\text { CL* } \\
\text { SSL* } \\
\text { ISL* } \\
\text { LF* }^{*}\end{array}$ & Combin39 & $\mathrm{K}$ : Nonlinear force-deflection curves & & [25] \\
\hline $\begin{array}{l}\text { Collagen fibres } \\
\text { Screws }\end{array}$ & $\begin{array}{l}\text { Combin39 } \\
\text { Solid187 }\end{array}$ & $\begin{array}{l}\mathrm{K}: \text { Nonlinear force-deflection curves } \\
\mathrm{E}=100,000 \mathrm{MPa}\end{array}$ & 0.3 & [26] \\
\hline
\end{tabular}

Asterisk superscripts indicate porcine material properties
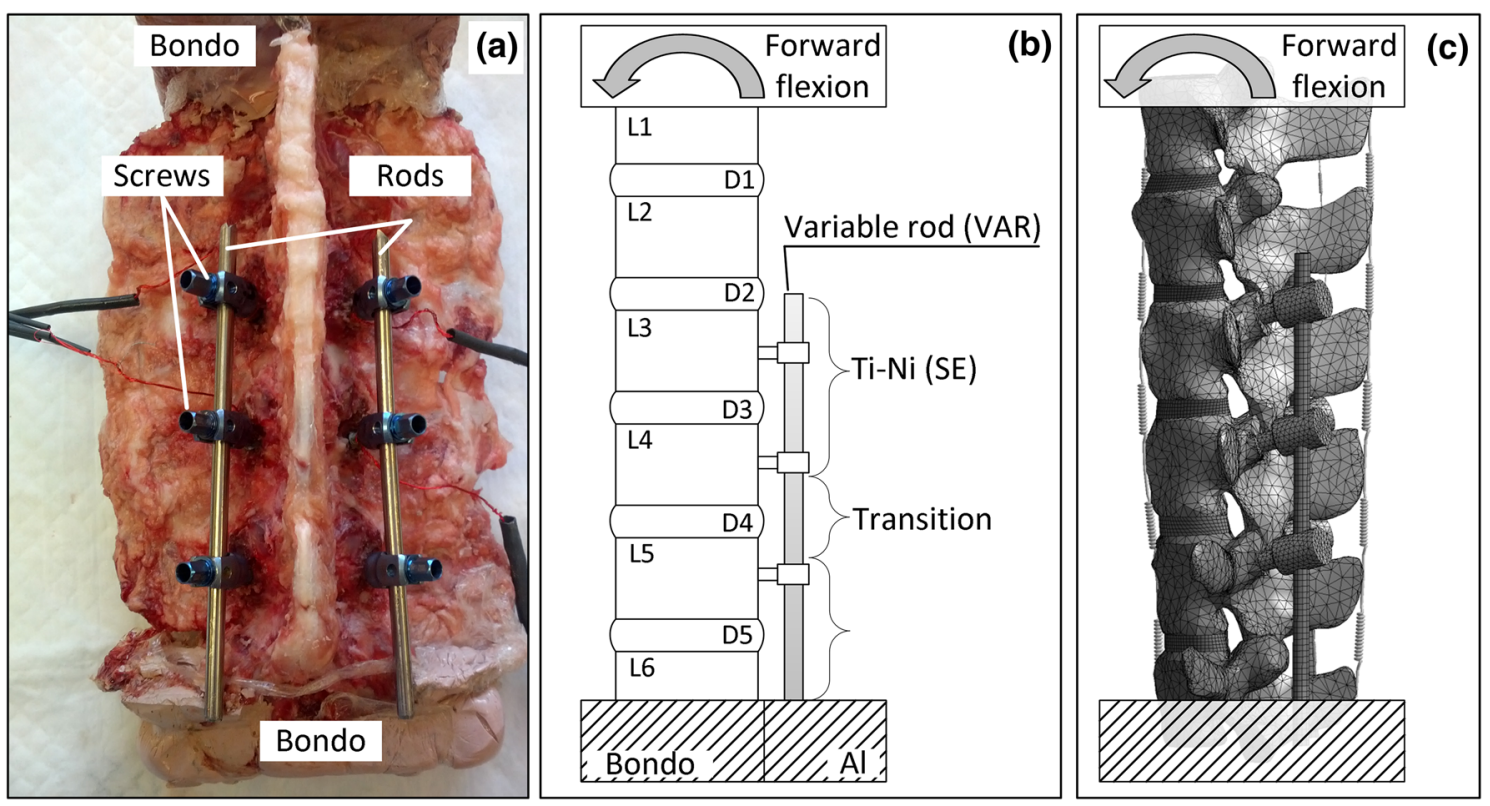

Fig. 5 a Posterior view of an instrumented specimen; b Schematic illustration of the VAR rod model on porcine specimen; and $\mathbf{c}$ illustration of meshed instrumented lumbar spine model

J-PDA at a maximum temperature of $410{ }^{\circ} \mathrm{C}$. Results from experiments (black bold lines) and from calculations (grey dotted lines) are presented. The temperature profile measured during J-PDA is also provided. In Fig. 6a, two bending profiles are presented: loading up to $91 \mathrm{~N}$ and then partial unloading to $47 \mathrm{~N}$. A good correlation is observed between the experiment and the calculation cases. In order to further validate the model, the same rod was loaded in cantilever bending at $91 \mathrm{~N}$, with its annealed part (Fig. 6b) and its hardened part (Fig. 6c) fixed. Once again, good agreement is observed between the experimental measurements and the results from the calculations.

\section{Porcine Spine Model Validation}

Figure 7 shows the comparison between the experimental and predicted ranges of motion in instrumented and uninstrumented conditions. Pure moment bending (displacement 
Fig. 6 a Temperature profile and bending profiles: (1) loading up to $91 \mathrm{~N}$, (2) partial unloading at $47 \mathrm{~N}$; bending profile for a similar rod with b the annealed end fixed, and c the hardened end fixed: experimental and numerically obtained data
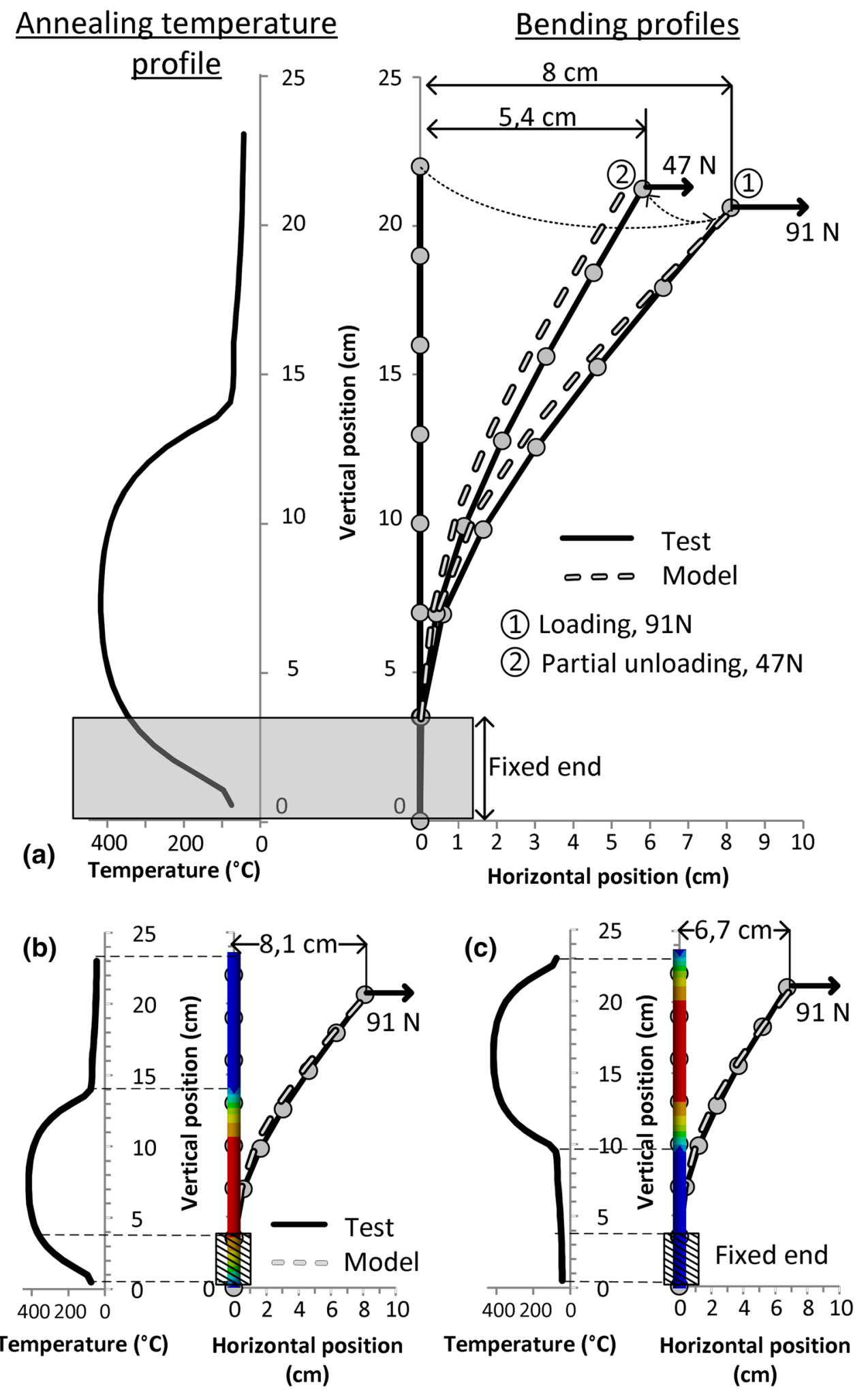

controlled) forward flexion up to $18^{\circ}$ was applied. In the uninstrumented condition, a good correlation is observed between the ranges of motion measured in vitro and those obtained by calculation. In the instrumented configuration, the mobility gradient observed between the stabilized and adjacent segments is also well reproduced. 
Fig. 7 Comparison between calculated and experimentally measured ranges of motion: a uninstrumented and b instrumented spine segments

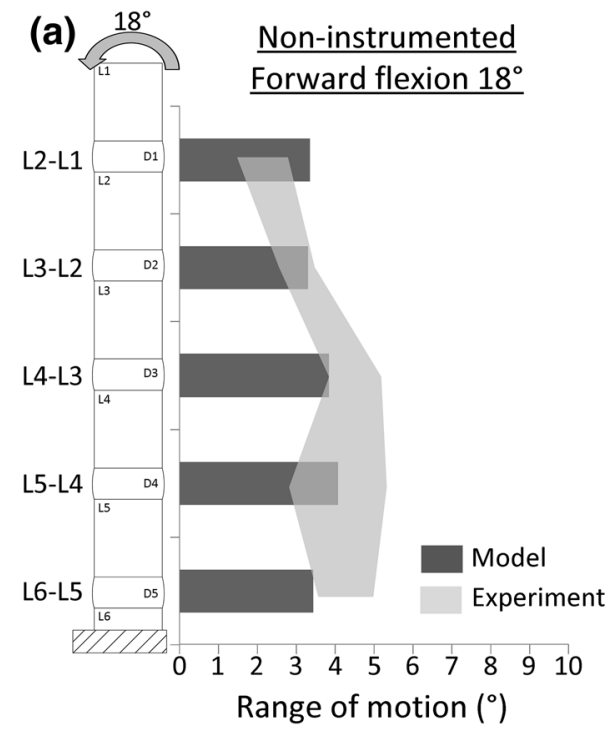

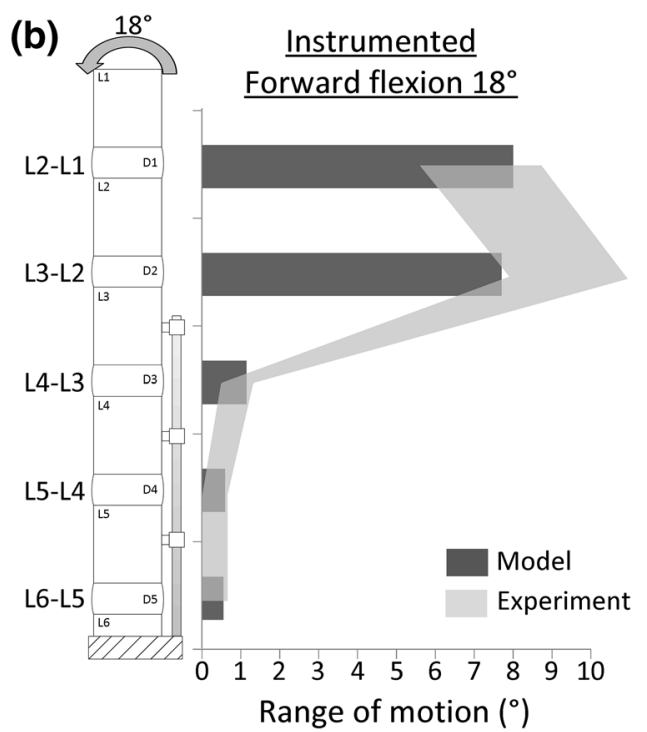

\section{Discussion}

Posterior instrumentations are commonly used in spinal fusion surgery. Rigid and solid implants composed of metallic rods and pedicle screws are used to provide the stability needed for fusion and to avoid implant failure, but can lead to adjacent segment disease. An ideal implant should combine static and dynamic properties, with higher stiffness where stability is critical, and lower stiffness where dynamic properties and load-sharing capacity is important. Such complexity of properties can be obtained by applying local Joule effect annealing on Ti-Ni rods.

In a previous study, an original Joule effect annealingbased manufacturing technique for producing Ti-Ni rods with variable flexural stiffness was proposed and validated [12]. This technology provides an easy, reliable and fast process to manufacture $\mathrm{Ti}-\mathrm{Ni}$ rods whose mechanical properties can be radically changed using annealing in as little as $10 \mathrm{~min}$.

Ti-Ni Ø5.5-mm rods ( $\mathrm{Ti}-55.94 \mathrm{Ni}$ wt\%) subjected to the aforementioned process were characterized using tensile testing. The results obtained indicate that stress-strain behaviour can range from classic elastoplastic (30\% cold work) to rubber-like with $30 \%$ elongation to failure $\left(585{ }^{\circ} \mathrm{C}, 10 \mathrm{~min}\right)$. Specimens exposed to J-PDA at $430{ }^{\circ} \mathrm{C}$ for 10 min exhibit superelastic behaviour. These observations are explained by the higher-temperature range of the martensitic transformation and the lower defect density after high-temperature J-PDA. This is in line with what was described by [7, 20, 21]). Cantilevered bending tests show that applying J-PDA locally leads to variable mechanical properties along the monolithic rod. Furthermore, such local treatments do not weaken the sample during fatigue testing [12].
A finite element model to simulate the impact of local annealing on the bending stiffness of spinal rods was implemented. The model successfully predicts the bending profiles for the locally annealed Ti-Ni alloy; as well, it appears promising for optimizing the heating schedule and predicting the mechanical property profiles resulting from local J-PDA.

A porcine lumbar 3D finite element model was implemented and validated under both uninstrumented and instrumented conditions. The model will be used to optimize the stiffness profile of the rod; it will further serve to develop and optimize new implants that aim to reduce excessive stress on the adjacent, intact segment. Various anchor configurations combining pedicle screws and transverse process hooks will also be investigated.

\section{Conclusion}

The aim of this work was (i) to manufacture Ti-Ni rods with variable flexural stiffness, (ii) to develop a finite element model simulating a porcine spine segment, and (iii) to assess the stabilization capacity of such a rod experimentally and numerically.

Local Joule annealing can be used to manufacture variable-stiffness Ti-Ni rods. It is possible to model the local annealing process and its effect on mechanical behaviour. The 3D finite element model of the instrumented spine segment was validated using experimental data. The model will be used to design and optimize new implants and decrease stress on the adjacent segment.

Acknowledgments This work was carried out with the financial support of the FQRNT (Fonds de Recherche du Québec-Nature et Technologies). 


\section{References}

1. Kotani $Y$ et al (1996) The role of spinal instrumentation in augmenting lumbar posterolateral fusion. Spine 21(3):278-287

2. Lorenz M et al (1991) A comparison of single-level fusions with and without hardware. Spine 16(8):455-458

3. Dewald CJ, Stanley T (2006) Instrumentation-related complications of multilevel fusions for adult spinal deformity patients over age 65: surgical considerations and treatment options in patients with poor bone quality. Spine 31(19):144-151

4. Hassanzadeh $\mathrm{H}$ et al (2013) Type of anchor at the proximal fusion level has a significant effect on the incidence of proximal junctional kyphosis and outcome in adults after long posterior spinal fusion. Spine Deform 1(4):299-305

5. Bono CM, Kadaba M, Vaccaro AR (2009) Posterior pedicle fixation-based dynamic stabilization devices for the treatment of degenerative diseases of the lumbar spine. J Spinal Disord Tech 22(5):376-383

6. Lee MJ, Lindsey JD, Bransford RJ (2010) Pedicle screw-based posterior dynamic stabilization in the lumbar spine. J Am Acad Orthop Surg 18(10):581-588

7. Brailovski V et al (2004) Foundations of heat and thermomechanical treatments and their effect on the structure and properties of titanium nickelide-based alloys. Phys Met Metallogr 97(Suppl 1):3-55

8. Otsuka K, Wayman CM (1999) Shape memory materials. Cambridge University Press, Cambridge

9. Bellouard $\mathrm{Y}$ et al. (1998) Local annealing of complex mechanical devices: a new approach for developing monolithic micro-devices. In: ICOMAT 98. International Conference on Martensitic Transformations, 7-11 Dec 1998. Elsevier, Switzerland

10. Mahmud AS, Yinong L, Tae-hyun N (2008) Gradient anneal of functionally graded NiTi. Smart Mater Struct 17(1):015031

11. Qinglin M et al (2012) Functionally graded NiTi strips prepared by laser surface anneal. Acta Mater 60(4):1658-1668

12. Facchinello Y et al (2013) Manufacturing of monolithic superelastic rods with variable properties for spinal correction: Feasibility study. J Mech Behav Biomed Mater 22:1-11

13. Orgeas L, Favier D (1995) Non-symmetric tension-compression behaviour of $\mathrm{NiTi}$ alloy. In: International Conference on Martensitic Transformation. ICOMAT 95, 20-25 Aug 1995. Editions de Physique, France

14. Facchinello Y et al (2014) Monolithic superelastic rods with variable flexural stiffness for spinal fusion: modeling of the processing-properties relationship. Med Eng Phys 36(11): $1455-1463$

15. Castellvi AE et al (2007) Stress reduction in adjacent level discs via dynamic instrumentation: a finite element analysis. SAS J. $1(2): 4-81$

16. Wilke HJ, Geppert J, Kienle A (2011) Biomechanical in vitro evaluation of the complete porcine spine in comparison with data of the human spine. Eur Spine J 20(11):1859-1868

17. Facchinello $\mathrm{Y}$ et al. (2014) Monolithic superelastic rods with variable flexural stiffness for spinal fusion: Simplified finite element analysis of an instrumented spine segment. In: 36th Annual International Conference of the IEEE Engineering in Medicine and Biology Society, 26-30 Aug 2014, Chicago

18. Facchinello Y et al (2015) Biomechanical assessment of the stabilization capacity of monolithic spinal rods with different flexural stiffness and anchoring arrangement. Clin Biomech 30(10):1026-1035

19. Facchinello Y et al. (2015) In-vitro assessment of the stabilization capacity of monolithic spinal rods with variable flexural stiffness: Methodology and Examples. In: 37th Annual International Conference of the IEEE Engineering in Medicine and Biology Society. 25-29 Aug 2015, Milan

20. Demers V et al (2006) Functional properties of nanostructured Ti50.0 at\% Ni alloys. J ASTM Int 3(6):1-11

21. Saburi T et al (1986) Effects of thermo-mechanical treatment on the shape memory effect and the pseudoelasticity of Ti-50.2 Ni and Ti-47. $5 \mathrm{Ni}-2.5 \mathrm{Fe}$ alloys. Tetsu To Hagane 72(6):571

22. Lin RM, Tsai KH, Chang GL (1997) Distribution and regional strength of trabecular bone in the porcine lumbar spine. Clin Biomech 12(5):331-336

23. Schmidt $\mathrm{H}$ et al (2007) Intradiscal pressure, shear strain, and fiber strain in the intervertebral disc under combined loading. Spine 7:748-755

24. Pintar FA et al (1992) Biomechanical properties of human lumbar spine ligaments. J Biomech 25(11):1351-1356

25. Aziz HN et al (2008) Porcine models in spinal research: calibration and comparative finite element analysis of various configurations during flexion-extension. Comp Med 58(2):174-179

26. Shirazi-Adl A, Ahmed AM, Shrivastava SC (1986) Mechanical response of a lumbar motion segment in axial torque alone and combined with compression. Spine 11(9):914-927 